\title{
Knowledge and attitude about antismoking legislation in Morocco according to smoking status
}

\author{
N. Tachfouti, ${ }^{1}$ K. El Rhazi, ${ }^{1}$ M. Berraho, ${ }^{7}$ M.C. Benjelloun, ${ }^{2}$ K. Slama ${ }^{3}$ and C. Nejjari ${ }^{7}$
}

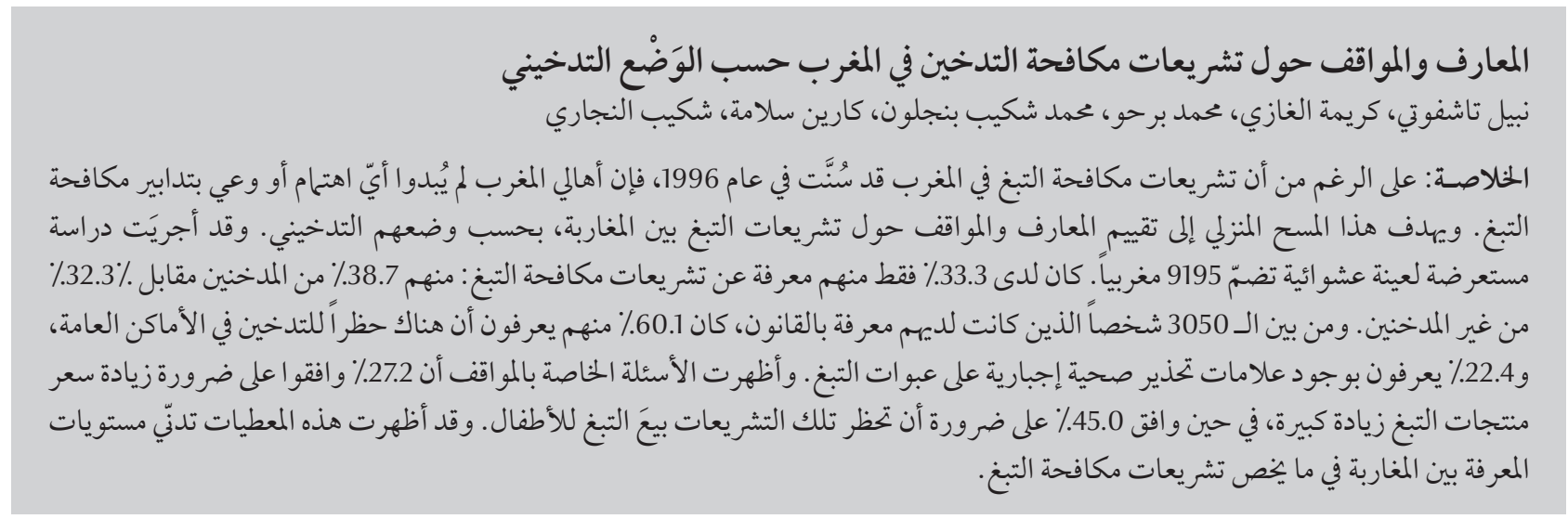

ABSTRACT Despite tobacco control legislation enacted in Morocco in 1996, the Moroccan population appears to have little interest in or awareness of tobacco control measures. This household survey aimed to assess knowledge and attitudes about tobacco legislation among Moroccans, according to their smoking status. A crosssectional study was conducted on a random sample of 9195 Moroccans. Only 33.3\% knew about the antismoking legislation: $38.7 \%$ of smokers versus 32.3\% of non-smokers. Among the 3050 people who knew about the law, $60.1 \%$ knew about the ban on smoking in public areas and $22.4 \%$ knew there was an obligatory health warning on tobacco packaging. The attitude questions showed that $27.2 \%$ agreed that the price of tobacco products should increase sharply and $45.0 \%$ that antismoking legislation should prohibit tobacco sales to children. These data demonstrate low levels of information among Moroccans concerning current tobacco control legislation.

\section{Connaissances et attitudes concernant la législation antitabac au Maroc en fonction du statut tabagique}

RÉSUMÉ En dépit de la législation antitabac votée en 1996 au Maroc, la population marocaine semble peu intéressée par les mesures de lutte antitabac ou faiblement sensibilisée en la matière. La présente enquête auprès des ménages visait à évaluer les connaissances et les attitudes concernant la législation antitabac dans la population marocaine, en fonction du statut tabagique. Une étude transversale a été conduite sur un échantillon sélectionné aléatoirement de 9195 Marocains. Seuls 33,3\% avaient connaissance de la législation antitabac : 38,7 \% étaient fumeurs et 32,3\% étaient non-fumeurs. Parmi les 3050 personnes interrogées qui avaient connaissance de la législation, 60,1 \% savaient qu'il était interdit de fumer dans les lieux publics et 22,4\% avaient vu la mise en garde sanitaire obligatoire figurant sur les paquets de tabac. Les questions concernant l'attitude ont révélé que 27,2 \% des répondants étaient en faveur d'une forte hausse du prix des produits de tabac et que 45,0\% souhaitaient que la vente de tabac aux enfants soit interdite par la législation. Ces données soulignent le faible niveau d'information des Marocains au sujet de la législation antitabac en vigueur dans leur pays.

'Laboratory of Epidemiology, Clinical Research and Community Health, Faculty of Medicine, Fez, Morocco (Correspondence to N. Tachfouti: tachfoutinabil@yahoo.fr).

${ }^{2}$ Department of Pneumology, Hassan II University Hospital Center, Fez, Morocco.

${ }^{3}$ International Union against Tuberculosis and Lung Disease (IUATLD), Paris, France.

Received: 21/07/09; accepted: 16/09/09 


\section{Introduction}

Two decades ago, cigarette smoking in Africa was referred to as the coming epidemic" [1]. This prediction has been confirmed, as many countries on the continent are now in the middle of the epidemic; the available information shows that the prevalence of smoking in African countries ranges from 17\% to $32 \%[2-5]$. The adoption and enforcement of legislative tobacco control measures $[6,7]$ are particularly needed in many African countries. There is a view that Africa has been targeted by the tobacco industry because there is little control of tobacco advertising [8]. Furthermore, in most African countries where there is no control over cigarette manufacture, the tobacco companies manufacture low-quality cigarettes that would not be sold in Europe and North America [9].

In Morocco a tobacco control law was enacted in 1996 [10]; it included bans on advertising, on sponsorship and on smoking in public transport and educational and health care facilities. The law requires that all packs of cigarettes display messages on both sides warning about the harmful effects of tobacco. Efforts to inform and educate the public about the health risks associated with tobacco consumption were later initiated. However, the law has not been strictly enforced and has generally not been respected by the general population. The law has therefore had little impact on tobacco use in a country where the average tobacco expenditure for households with a daily smoker is $30 \%$ of total income [11]. The most recent data shows that between 2000 and 2006, smoking increased from $17.2 \%$ to $18.5 \%$ among adults aged over 20 years $[12,13]$, and from $13.9 \%$ to $15.5 \%$ among youth aged 13-15 years. Moreover, the overall prevalence of exposure to environmental tobacco smoke among school students increased from $27.7 \%$ to $30.0 \%[14,15]$.
In July 2008, the Moroccan parliament unanimously approved a new law which modified and reinforced the previous law. It prohibits smoking in certain enclosed public places, such as coffee shops and restaurants, and bans advertising or publicity for tobacco in specified places. The sale of cigarettes to minors is also prohibited and punishable by a fine. Mandatory fines are imposed for non-compliance with the law. Half of the collected fines are to be paid to nongovernmental organizations (NGOs) working to educate people about the dangers of smoking

Despite the legislation, there remains a widespread view that the Moroccan population has little interest in, or awareness of, tobacco control. Data on the knowledge and attitudes of Moroccans about tobacco control policies and legislation are, however, not available. This study examined the public's knowledge of and attitudes to general and specific tobacco control policies in Morocco, with an emphasis on differences according to smoking status.

\section{Methods}

\section{Population}

A cross-sectional study of a representative sample of the Moroccan population was conducted in 2006 (the Maroc Tabagisme survey). A multi-stage, stratified probability sampling design of 7 administrative regions, representing $43.8 \%$ of the total population, was adopted using protocol recommendations of the International Union against Tuberculosis and Lung Diseases (IUTLD) and in line with the Moroccan population census of 2004 [16].

In each administrative region, a prefecture was randomly chosen according to the size of the population. The sample was selected in 2 stages: first, each prefecture was grouped into 2 strata with probability proportional to size within each primary sampling unit selected. The first stratum was the prefecture centre covering the urban area and the second stratum included the surrounding villages. In each urban area 3 districts were defined as low, middle and high income using the Moroccan population census criteria of the socioeconomic levels of residential areas [16]. Residential districts of each socioeconomic category were then selected according to the size of the population. A random sample of households was visited in each stratum.

After giving informed consent to participate and reassurance of the confidentiality of their responses, individuals aged 15 years and above in the selected household were invited, alternating between males, females and children, to participate in the survey. The desired total sample size was established as 9000 individuals, with an alpha error of 5\%. The sample was large enough to obtain sufficient numbers of smokers and nonsmokers so as to study factors related to each of these groups.

\section{Data collection}

A questionnaire was developed based on a tobacco questionnaire devised by the IUTLD [17]. A French version of the questionnaire was then developed by the Department of Epidemiology and Public Health in Fez with IUTLD collaboration. The questionnaire was also translated into Moroccan Arabic dialect. The revised version was subjected to a pilot survey and the final form was adapted and refined on the basis of the results of the pilot study.

The questionnaire was administered face-to-face to the head or any other competent adult member of the household. The questions covered demographic variables, smoking behaviour (how many cigarettes smoked in their lifetime, number of cigarettes smoked, whether a daily or occasional smoker) and exposure to passive smoking (by family members or work colleagues). Respondents were also asked about their knowledge of the existence of the law and about specific aspects of the 
law. They were also asked whether or not they favoured each of the 5 tobacco control legislative measures included in the World Health Organization Framework Convention on Tobacco Control [7]: smoking bans in public places, increasing cigarette taxes, tobacco advertising bans, health warnings on cigarette packs and banning sales to children.

Respondents were classified as smokers or non-smokers. Smokers were those who had smoked at least 100 cigarettes in their lifetime and who still smoked daily or occasionally (current smokers) at the time of TB diagnosis or had recently stopped (for less than 3 months). Non-smokers were those who had never smoked or had smoked fewer than 100 cigarettes prior to the date of the interview or had smoked at least 100 cigarettes in their lifetime, but had quit for more than 3 months.

\section{Analysis}

Statistical analyses were performed using Epi-Info software, version 3.3.2. Chi-squared tests were conducted to examine differences in attitudes towards 5 legislative measures included in the WHO Framework Convention on Tobacco Control according to smoking status. Missing cases were not included in the analysis.

\section{Results}

\section{Smoking status}

A total of 9195 subjects, i.e. 1 per household, were included in the survey (Table 1); $51.7 \%$ of respondents $(n=4753)$ were men. The mean age was 31.1 (SD $13.7)$ years; $53.2 \%$ of the sample were aged $<30$ years, $37.3 \%$ lived in rural areas and $45.5 \%$ were either illiterate or had a very low educational level.

Table 1 shows that the prevalence of smoking according to sex and sociodemographic characteristics. The overall prevalence of current smoking was reported to be $18.0 \%$ (95\% CI: $17.2 \%-$ 18.8\%): $31.5 \%$ (95\% CI: $30.2 \%-32.9 \%)$ in males and $3.3 \%$ ( $95 \% \mathrm{CI}: 2.8 \%-3.8 \%$ ) in females. According to residential area, the prevalence of current smoking was $16.9 \%$ in rural and $18.6 \%$ in urban areas. Among men, the highest proportion of smokers was among those aged 30-50 years (40.4\%) and among the illiterate (39.0\%). The prevalence of smoking was inversely associated with level of education in men but increased with educational level in women.
Environmental tobacco smoke exposure at home was reported by $41.7 \%$ of respondents, but the proportion who had passive smoke exposure at worksites was much higher (62.4\%).

\section{Knowledge about tobacco legislation}

Table 2 summarizes respondents' knowledge of the existence of the tobacco legislation according to their sociodemographic characteristics. Among respondents, 3050 (33.5\%) overall knew of the existence of the law: $39.5 \%$ of men and $27.0 \%$ of women. The proportion who knew about the law was higher among smokers (38.7\% versus $32.3 \%$ ), people living in urban areas (35.8\% versus $29.4 \%$ ) and those with the highest educational level (rising from $17.1 \%$ among illiterates to $56.5 \%$ of those with a university degree).

\section{Knowledge of tobacco control measures}

Knowledge of key tobacco control measures contained in the law was variable among respondents who knew that a law existed. Table 3 illustrates the knowledge about tobacco control measures according to sex and smoking status. Men were more informed

\begin{tabular}{|c|c|c|c|c|c|c|}
\hline \multirow[t]{3}{*}{ Variable } & \multicolumn{3}{|c|}{ Males } & \multicolumn{3}{|c|}{ Females } \\
\hline & Total & Smokers & $P$-value & Total & Smokers & $P$-value \\
\hline & No. & $\%$ & & No. & $\%$ & \\
\hline Age (years) & & & $<0.01$ & & & $<0.01$ \\
\hline $15-30$ & 2519 & 27.0 & & 2371 & 3.9 & \\
\hline $30-50$ & 1602 & 40.4 & & 1561 & 2.8 & \\
\hline$>50$ & 632 & 27.7 & & 440 & 1.6 & \\
\hline Residence & & & NS & & & $<0.001$ \\
\hline Urban & 2907 & 31.9 & & 2741 & 4.6 & \\
\hline Rural & 1816 & 30.9 & & 1615 & 1.1 & \\
\hline Educational level & & & $<0.01$ & & & $<0.001$ \\
\hline Illiterate & 544 & 39.0 & & 1072 & 1.5 & \\
\hline Basic/primary & 1483 & 32.2 & & 1080 & 1.8 & \\
\hline Secondary & 1683 & 29.3 & & 1419 & 4.2 & \\
\hline University degree & 996 & 29.8 & & 765 & 6.0 & \\
\hline Total & 4753 & 31.5 & & 4442 & 3.3 & \\
\hline
\end{tabular}




\begin{tabular}{|c|c|c|c|}
\hline $\begin{array}{l}\text { Table } 2 \text { Knowledg } \\
\text { respondents' socic }\end{array}$ & $\begin{array}{l}\text { tence } 0 \\
\text { charact }\end{array}$ & $\begin{array}{l}\text { obacco control la } \\
s\end{array}$ & cording tc \\
\hline Variable & Total & Knew about law & $P$-value \\
\hline & No. & $\%$ & \\
\hline Sex & & & $<0.01$ \\
\hline Male & 4753 & 39.5 & \\
\hline Female & 4442 & 27.0 & \\
\hline Residence & & & $<0.01$ \\
\hline Urban & 2907 & 35.8 & \\
\hline Rural & 1816 & 29.4 & \\
\hline Education level & & & $<0.01$ \\
\hline Illiterate & 544 & 17.1 & \\
\hline Basic & 1483 & 31.2 & \\
\hline Primary & 1683 & 23.7 & \\
\hline Secondary & 996 & 35.6 & \\
\hline University degree & & 56.5 & \\
\hline Smoking status & & & $<0.01$ \\
\hline Smoker & 1631 & 38.7 & \\
\hline Non smoker & 7471 & 32.3 & \\
\hline
\end{tabular}

than women on the contents of the law. Only $31.0 \%$ of men and $27.0 \%$ of women knew about the ban on tobacco advertising. More than half of the study population knew about the ban on smoking in public areas: $61.2 \%$ of males and $58.6 \%$ of females. Only $11.1 \%$ of males and $11.9 \%$ of females knew about the ban on selling tobacco to children.

Among women, significantly more non-smokers than smokers knew about the ban on advertising, but in males there was no significant difference according to smoking status (Table 3). More non-smokers than smokers knew about the ban on smoking in public for both males $(63.2 \%$ versus $56.7 \%)$ and females (59.3\% versus $45.3 \%)$.

\section{Attitudes to strategies for reducing smoking}

Table 4 shows the opinions of the respondents about how to reduce smoking: $34.8 \%$ felt that there should be a complete ban on advertising, $34.8 \%$ agreed that smoking should be restricted in public places and $45.0 \%$ said that cigarette sales to children aged younger than 16 years should be prohibited.
There were significant differences for 2 of 5 suggested regulations according to smoking status. Smokers were less favourable to the idea of an increase in tobacco product prices $(24.5 \%$ versus $27.8 \%)$ and about health warnings on packets (19.0\% versus $22.0 \%$ ).

\section{Discussion}

This study reports knowledge and attitudes toward tobacco control in a representative sample of the Moroccan population. Some limitations of the study need to be discussed; first, participants were not of similar age to the national population and the survey included only adults aged 18 years and over. Moreover, we used self-reported data on smoking, which may result in underreporting of smoking due to its negative sociocultural connotations, especially among the youngest ages and among females. However, this is the first study that provides information about the prevalence, knowledge and attitudes about smoking in Morocco, as the number of respondents in this study $(n=9195)$ was large enough to

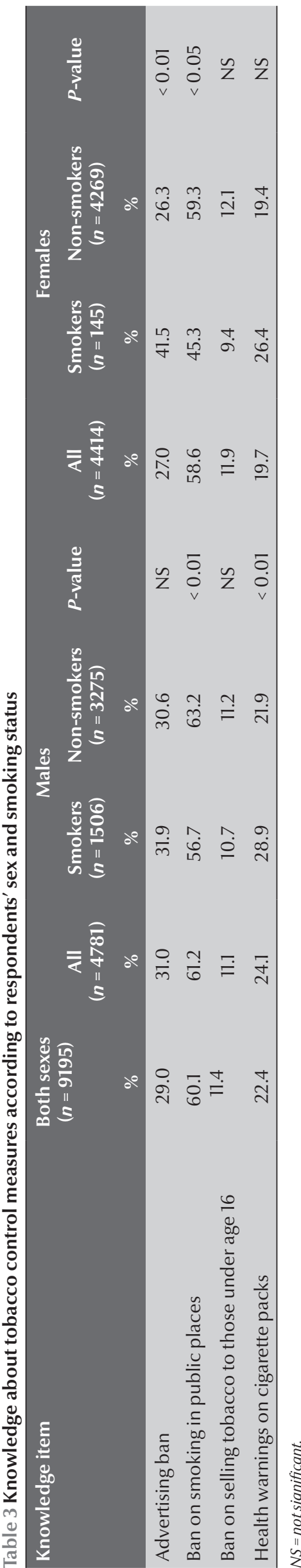




\begin{tabular}{|c|c|c|c|c|}
\hline \multirow[t]{2}{*}{ Attitude item } & $\begin{array}{c}\text { All } \\
(n=3050)\end{array}$ & $\begin{array}{c}\text { Smokers } \\
(n=631)\end{array}$ & $\begin{array}{l}\text { Non-smokers } \\
(n=2399)\end{array}$ & $P$-value \\
\hline & $\%$ & $\%$ & $\%$ & \\
\hline Cigarette packs should contain health warnings & 19.5 & 19.0 & 22.0 & $<0.05$ \\
\hline Smoking in public places should be prohibited & 34.8 & 36.6 & 34.4 & $\geq 0.05$ \\
\hline Price of tobacco products should increase sharply & 27.2 & 24.5 & 27.8 & $<0.01$ \\
\hline Cigarette sales to children should be prohibited & 45.0 & 45.9 & 44.9 & $\geq 0.05$ \\
\hline Tobacco advertising should be completely banned & 34.8 & 36.6 & 34.4 & $\geq 0.05$ \\
\hline
\end{tabular}

represent the national population, and to compare attitudes of self-reported smokers with those of non-smokers.

These data show a weak level of knowledge about the law among the Moroccan population despite the first enactment of the law more than 10 years ago. Only 33.5\% of the survey population knew about the law and, among them, no more than $11.0 \%$ knew of the ban on selling tobacco to minors. The highest level of knowledge was among those with a university degree.

Small proportions of smokers and non-smokers indicated their support for tobacco control measures. Only about a third supported a ban on advertising. Similar results were found in Turkey (24.5\% supported advertising bans), whereas greater support from the public has been reported in China and the United States [18,19].

Less than $35 \%$ of the respondents in Morocco favoured a ban on smoking in public places, a figure which is lower than among the general public in Taiwan [20]. The more favourable support in Taiwan might be due to the extensive government efforts to combat tobacco use in Taiwan, which were supplemented by tobacco-counter advertising and mass media campaigns [21]. Actually, the overall low awareness of the law and relatively limited support for some measures of tobacco control among Moroccans indicate that public awareness campaigns and the general enforcement of existing laws are limited and ineffective.

In 2004, a great deal of publicity was generated by the purchase of the Moroccan Tobacco Monopoly by Altadis, a multinational manufacturer and distributor of cigarettes. Positive promotional efforts by that company may have played a role in the relatively small proportions of the population supporting tobacco control measures.

A less favourable attitude towards preventive legal measures, especially protection of children, was shown by smokers than by non-smokers. The results emphasize the need for better information on the different specific aspects of the law and the need for better enforcement of the regulations. About $27.2 \%$ of our respondents were supportive of increased taxes on cigarettes; some studies report that smokers are less likely to support a cigarette tax than non-smokers [22]. This is true in our sample as well, but even non-smokers showed low support for such a measure. This again indicates a lack of efforts to inform the public and generate support for tobacco control measures including price policy.

In the WHO Eastern Mediterranean Region each country displays varying strengths and weaknesses concerning tobacco control. In Egypt, cigarette consumption is the highest in the Middle East. Legislation restricts smoking in some public places, such as work and other enclosed areas, but taxes on cigarettes are low [23]. Jordan has prohibited tobacco sales to minors and became the first country in the region to place prominent health warnings on cigarette packets. Despite these efforts, a Jordanian Ministry of Health survey found that smoking increased from $27 \%$ to $29 \%$ between 2005 and 2007 [23]. With Morocco now moving towards ratifying the WHO Framework Convention on Tobacco Control, which contains comprehensive anti-smoking policies [24], the need to adapt and enforce effective legislation becomes crucial. To implement tobacco control strategies successfully and to improve their effectiveness, knowledge about the impact of tobacco legislation and other tobacco control activities should be monitored regularly in terms of prevalence of use, public attitudes, socioeconomic patterns and health indicators.

\section{Acknowledgements}

We thank the Moroccan Health Ministry for having authorized the survey and the International Union Against Tuberculosis and Lung Diseases for its support and help.

We also thank Dr Jean-François Tessier for his contribution and assistance and we thank all the interviewers for their participation in gathering the information. 


\section{References}

1. Taha A, Ball K. Smoking in Africa: the coming epidemic. World Smoking \& Health, 1982, 7:25-30.

2. Koffi $\mathrm{N}$ et al. [Smoking in the African setting (Abidjan, Ivory Coast): patient knowledge, attitude and behavior.] Connaissances, attitudes et comportements des patients vis-a-vis du tabagisme en milieu africain a Abidjan (Cote d'Ivoire) Revue de Pneumologie Clinique, 2004, 60:217-222.

3. Mpabulungi L, Muula AS. Tobacco use among high school students in Kampala, Uganda: questionnaire study. Croatian Medical Journal, 2004, 45:80-83.

4. Kwamanga DH, Odhiambo JA, Amukoye El. Prevalence and risk factors of smoking among secondary school students in Nairobi. East African Medical Journal, 2003, 80:207-212.

5. Youssef RM, Abou-Khatwa SA, Fouad HM. Prevalence of smoking and age of initiation in Alexandria, Egypt. Eastern Mediterranean Health Journal, 2002, 8:626-637.

6. Botelho A et al. Environmental tobacco smoke risk perception and smoking behavior in Portugal. Lison, Portugal, Ministry of Science and Technology, 2008.

7. Report on the WHO framework convention on tobacco control. Geneva, World Health Organization, 2008.

8. Chapman $\mathrm{S}$ et al. All Africa conference on tobacco control. British Medical Journal, 1994, 308:189-191.

9. Awotedu AA, Higenbottam TW, Onadeko BO. Tar, nicotine, and carbon monoxide yields of some Nigerian cigarettes. Journal of Epidemiology and Community Health, 1983, 37:218-220.

10. [Dahir No. 1-91-112 of 26 June 1995 promulgating Law No. 15-91 prohibiting smoking and advertising or publicity for tobacco in certain places]. Rabat, Morrocco, General Secretariat of the Government, Bulletin official, 1995, $4318: 542$ [in Arabic].

11. Tachfouti $\mathrm{N}$ et al. Socioeconomic status and tobacco expenditures among Moroccans: results of the "Maroc Tabagisme" survey. American Journal of Health Promotion, 2010, 24:334-339.

12. Tazi MA, Abid-Khalil S, Chaouki N. Prevalence of the main cardiovascular risk factors in Morocco: results of a national survey in 2000. Journal of Hypertension, 2003, 21:897-903.
13. El Rhazi K et al. Inequalities in smoking profiles in Morocco: the role of educational level. International Journal of Tuberculosis and Lung Disease, 2008, 12:1327-1332.

14. Cherqaoui S, Tazi MA, Chaouki N. Rapport de l'enquête épidémiologique sur le tabagisme chez les jeunes scolarisés au Maroc. Rabat, Morocco, Ministry of Health, 2002:10.

15. Fact sheet: Eastern Mediterranean Region. Global Youth Tobacco Survey (GYTS): Morocco. Centers for Disease Control and Prevention [website] (http://www.cdc.gov/tobacco/global/ gyts/factsheets/emr/2001/morocco_factsheet.htm, accessed 16 January 2011).

16. Rapport national du recensement general de la population et de l'habitat de 2004. Rabat, Haut Commissariat au Plan, 2001.

17. Tobacco or health: a global status report. Geneva, World Health Organization, 1997.

18. Biener L, McCallum-Keeler G, Nyman AL. Adults' response to Massachusetts anti-tobacco television advertisements: impact of viewer and advertisement characteristics. Tobacco Control, 2000, 9:401-407.

19. Yang T et al. Attitudes and behavioral response toward key tobacco control measures from the FCTC among Chinese urban residents. BMC Public Health, 2007, 7:248.

20. Tsai $Y W$ et al. Public opinion regarding earmarked cigarette tax in Taiwan. BMC Public Health, 2003, 3:i42.

21. Levy DT et al. Increasing taxes to reduce smoking prevalence and smoking attributable mortality in Taiwan: results from a tobacco policy simulation model. Tobacco Control, 2005, 14(Suppl. 1):i45-i50.

22. Schumann A et al. Attitudes towards smoking policies and tobacco control measures in relation to smoking status and smoking behaviour. European Journal of Public Health, 2006, 16:513-519.

23. Gavlak D. Smoke alarm from Afghanistan to Morocco. Bulletin of the World Health Organization, 2008, 86:89-90.

24. Gilmore $A B$, Collin J. The world's first international tobacco control treaty. BMJ (Clinical Research Ed.), 2002, 325:846-847. 